\title{
PEMANFAATAN MATERIAL LOKAL DALAM PEMBUATAN ASPAL PORUS TIPE AC-WC YANG AMAN DAN RAMAH LINGKUNGAN
}

\author{
Amiruddin $^{1}$, Ibrahim $^{2}$, Ika Sulianti $^{3}$, Agus Subrianto $^{4}$ \\ ${ }^{1}$ Politeknik Negeri Sriwijaya \\ ${ }^{2}$ Politeknik Negeri Sriwijaya \\ ${ }^{3}$ Politeknik Negeri Sriwijaya \\ ${ }^{4}$ Politeknik Negeri Sriwijaya \\ E-mail: aekpanas@gmail.com
}

\begin{abstract}
Surface of highway pavement is wet during rain and drowned by stormwater. This situation can makes slip of vehicle wheels and causes an accident. Porous asphalt is a new generation in flexible pavement. Porous charactheristic can be obtained by using less fine aggregates comparing the normal one so it has more voids. We can expect the pavement has higher skid resistance and its voids can be functioned as drainage in mix. This type of pavement developement also strongly depends on availability of the approriate local material for that we can produce a good performance porous asphalt which is described in this paper. Consideration of so many problems can be taken apart, the research is limited in modification design of asphalt concrete wearing course using porous asphalt mix exploits South Sumatera aggregates. After investigatives classification of aggragates, the fine aggregates (sand) can be reduced significantly to obtain a large amount of voids by $6.1 \%$ asphalt used. However, this porous structure also causes defect, mainly the stability degradation in mix. So the future research will continue to formularize a better stability performance from pavement variety expected
\end{abstract}

Keywords: Porous Asphalt, Wearing Course

\begin{abstract}
ABSTRAK
Kondisi fisik jalan saat hujan terdapat air yang menggenangi permukaan jalan sehingga jalan menjadi licin yang dapat membuat roda kendaraan tergelincir dan menyebabkan kecelakaan. Aspal porus merupakan generasi baru dalam perkerasan lentur. Sifat porus diperoleh karena campuran ini menggunakan agregat halus lebih sedikit dibanding campuran normal sehingga memiliki kandungan rongga / pori lebih besar yang diharapkan memiliki kekesatan yang tinggi dan pori dapat berfungsi sebagai saluran drainase di dalam campuran. Pengembangan aspal jenis ini sangat tergantung dari ketersediaan material lokal yang cocok sehingga dapat dibuat aspal porus yang baik. Oleh karena itu penulis akan membuat modifikasi dan pemanfaatan material lokal agar dapat dibuat tipe aspal porus yang bermutu baik. Dikarenakan demikian luasnya permasalahan yang dapat dilakukan, maka pada tahap ini peneliti membatasi masalah pada modifikasi desain aspal wire course agar dapat dibuat menjadi aspal aspal porus menggunakan gradasi material lokal Sumatera Selatan. Dari penelitian yang dilakukan, didapatkan persentase pengurangan gradasi pasir yang signifikan untuk mendapatkan pori yang cukup dengan kadar aspal yang digunakan sebesar 6.1\%. Sebagai pengaruh dari pengurangan pasir di dalam campuran berakibat penurunan stabilitas pada campuran, untuk itu disarankan penelitian lebih lanjut untuk dapat mencari komposisi yang optimal dengan stabilitas yang baik.
\end{abstract}

Kata kunci: Aspal Poros, Lapisan Aus 


\section{PENDAHULUAN}

Jalan merupakan prasarana transportasi yang paling banyak digunakan oleh masyarakat Indonesia untuk melakukan mobilisasi keseharian. Kondisi fisik jalan, terutama saat hujan terdapat air yang menggenangi permukaan jalan sehingga jalan menjadi licin yang dapat membuat roda kendaraan tergelincir dan menyebabkan kecelakaan. Campuran beraspal masih merupakan lapis penutup perkerasan jalan yang dominan di Indonesia. Salah satu jenis campuran beraspal adalah aspal porus yang merupakan salah satu jenis perkerasan jalan yang telah dikembangkan di beberapa negara maju dan diperuntukkan hanya pada lapisan aus atau penutup (wearing course). Aspal porus merupakan generasi baru dalam perkerasan lentur. Sifat porus diperoleh karena campuran ini menggunakan agregat halus lebih sedikit dibanding campuran lain sehingga memiliki kandungan rongga / pori lebih besar yang diharapakan memiliki tingkat kekesatan yang tinggi dan pori dapat berfungsi sebagai saluran drainase di dalam campuran. Rongga / pori tersebut memungkinkan air dapat meresap langsung secara vertical dan horizontal menuju ke tepi badan jalan dan kemudian masuk ke saluran samping.

Penelitian ini dilakukan dengan menggunakan material lokal Sumatera Selatan yang pepuler berasal dari Lahat guna mengetahui komposisi campuran aspal porus dengan menggunakan perbandingan persentase agregat pada gradasi yang diuji sesuai acuan JMF aspal AC - WC dengan pengujian Marshall. Dari hasil penelitian ini diharapkan dapat memperoleh alternatif campuran aspal porus berbahan baku lokal yang memiliki kadar rongga yang besar untuk meneruskan aliran air ke saluran samping sehingga dapat mengurangi genangan air diatas permukaan jalan yang biasa terjadi akibat hujan. Dalam pelaksanaan aspal di banyak Negara untuk jenis aspal porous ini digunakan untuk jalan yang tidak berkapasitas tinggi namun memiliki kekuatan yang cukup, dan dikembangkan dengan komposisi yang berbeda beda di setiap Negara. Pengembangan aspal jenis ini sangat tergantung dari ketersersediaan material lokal yang cocok sehingga dapat di buat aspal porous yang baik. Oleh Karena itu penulis akan membuat modifikasi dan pemanfaatan material lokal agar dapat dibuat type aspal porous yang bermutu baik. Dikarenakan demikian luasnya permasalahan yang dapat di lakukan penelitian maka peneliti pada tahap ini membatasi masalah yang akan diteliti pada modifikasi desain aspal wire course agar dapat di buat menjadi aspal porous dengan menggunakan gradasi material lokal Sumatera Selatan.

Penelitian ini dikembangkan melalui beberapa referensi yang berhubungan dengan objek pembahasan sebagai suatu batasan studi dimana didalamnya memuat hal-hal yang harus dikerjakan dan hal-hal yang tidak perlu dikerjakan dalam penelitian, serta asumsi-asumsi yang diambil untuk mempermudah penyelesaian penelitian ini. Di Jepang, Belanda dan sejumlah negara lainnya telah menggunakan aspal berongga sebagai jalan utama (Miradi dkk., 2009) dan (Katsuji dkk., 2009), termasuk di Indonesia, aspal porus gradasi Australia secara umum diaplikasikan pertama kali pada proyek jalan tol Jagorawi dan jalan tol Tangerang-Jakarta, pada tahun 1997. Aspal porus adalah campuran aspal dengan agregat tertentu yang didesain setelah dipadatkan mempunyai pori-pori udara berkisar20,00\%. (Khalid \& Jimenes, 1994). Permasalahan utama yang dijumpai pada aspal porus konvensional satu lapis (single function), hal ini disebabkan terjadinya penyumbatan (clogging) rongga oleh debu. Permasalahan ini sudah dapat dikurangi dengan menerapkan lapisan aspal porus dua lapis (twinlay). Seperti yang disajikan (Borchove, 1996).

Aspal porus adalah aspal yang dicampur dengan agregat tertentu yang setelah dipadatkan mempunyai $20 \%$ pori-pori udara dan umumnya memiliki nilai stabilitas Marshall yang lebih rendah dari beton aspal yang menggunakan gradasi rapat, stabilitas Marshall akan meningkat bila gradasi terbuka yang digunakan lebih banyak fraksi halus (Cabrera dkk., 1996). Aspal poros merupakan salah satu alternatif untuk meningkatkan keselamatan di jalan dan mengurangi kebisingan (noise reduction). 
Aspal poros didesain untuk mendapatkan kadar rongga yang besar untuk meneruskan aliran air ke saluran samping dan lapisan dasar yang kedap air untuk mencegah air meresap ke lapis subbase dan badan jalan sehingga genangan air di atas permukaan jalan yang seringkali terjadi setelah hujan dan mengganggu kelancaran arus lalu lintas dapat diminimalisir. Kondisi ini dimungkinkan karena gradasi yang digunakan merupakan gradasi terbuka yang memiliki fraksi agregat kasar tidak kurang dari 85\% dari berat total campuran. (Media Teknik Sipil, Setyawan A. Sanusi, 2005).

Menurut Sukirman (1999) kerusakan-kerusakan pada konstruksi perkerasan jalan dapat disebabkan oleh lalulintas, air, konstruksi perkerasan, iklim, kondisi tanah dasar yang tidak stabil, proses pemadatan lapisan di atas tanah yang kurang baik. Dalam penelitian ini, kerusakan akibat penggenangan air di permukaan aspal diharapkan dapat diminimalisir dengan menggunakan campuran material yang diteliti.

\section{METODE/PERANCANGAN PENELITIAN}

Penelitian ini dilakukan dengan dua tahap yaitu penelitian sekala laboratorium yang nantinya ditahap berikutnya akan dilanjutkan penelitian ke tahap percobaan dilapangan langsung setelah hasil penelitian ditahap ini selesai dengan membuat model sesungguhnya dalam ukuran kecil. Metode yang digunakan dalam penelitian ini merupakan penelitian dengan pengujian dilaboratorium dan pengujian lapangan dengan menggunakan variable komposisi dengan campuran dengan prosentase aggregat halus yang berbeda sampai didapatkan kondisi optimum yaitu, $0 \%, 15 \%, 30 \%, 45 \%$ dan $60 \%$ dengan pengujian menggunakan methode Marshall.

Penelitian ini dilakukan di Laboratorium Jurusan Teknik Sipil Politeknik Negeri Sriwijaya dan pengambilan material dilakukan di sekitar kota Palembang dan untuk aspal digunakan dari PT. Rabana Aspalindo Bom Baru Palembang

Tahapan-tahapan pembuatan spesimen dalam penelitian ini adalah sebagai berikut :

1. Pengujian Material (Sifat Fisik Bahan)

2. Kontrol Spesifikasi

3. Pembuatan Job Mix Formula (Mix Design)

4. Pembuatan Sampel Untuk Marshall Test

5. Analisa Data Untuk Mendapatkan Kadar Aspal Optimum

6. Membuat Benda Uji Berupa Layer Skala Mini Di Lapangan Untuk Pengujian Porositas Lapisan Perkerasan.

\section{HASIL DAN PEMBAHASAN}

\section{Pengujian Material dan Aspal}

Pengujian dilakukan untuk mendapatkan nilai sifat-sifat fisik agregat dan pengujian karakteristik aspal yang sesuai dengan spesifikasi SNI (Standar Internasional Indonesia) dari hasil-hasil pengujian dilakukan akan dapat diketahui rancangan komposisi campuran sebuah benda uji.

Serangkaian pengujian yang telah dilakukan menunjukkan hasil-hasil yang disajikan berupa pengujian agregat pada Tabel 1 dan pengujian aspal pada Tabel 2 sebagai berikut : 
Tabel 1. Hasil Pengujian Sifat Fisik Agregat

\begin{tabular}{|c|c|c|c|c|c|c|}
\hline \multirow{4}{*}{ Jenis Pengujian } & \multicolumn{4}{|c|}{ Hasil } & \multirow{4}{*}{ Satuan } & \multirow{4}{*}{ Spesifikasi } \\
\hline & \multicolumn{2}{|c|}{ Agregat Halus } & \multicolumn{2}{|c|}{ Agregat Kasar } & & \\
\hline & Abu Batu & Pasir & Agregat 1/1 & Agregat 1/2 & & \\
\hline & $\begin{array}{c}\text { Lolos } \\
\text { saringan 9,5 }\end{array}$ & $\begin{array}{c}\text { Lolos } \\
\text { saringan } \\
9,5 \\
\end{array}$ & $\begin{array}{c}\text { Lolos } \\
\text { saringan } \\
12,5 \\
\end{array}$ & $\begin{array}{c}\text { Lolos } \\
\text { saringan } 19\end{array}$ & & \\
\hline Berat Jenis Bulk & 2,490 & 2,426 & 2,673 & 2,585 & - & $\operatorname{Min} 2,5$ \\
\hline Berat Jenis SSD & 2,559 & 2,492 & 2,741 & 2,635 & - & $\operatorname{Min} 2,5$ \\
\hline Berat Jenis Semu & 2,674 & 2,599 & 2,869 & 2,703 & - & $\operatorname{Min} 2,5$ \\
\hline Berat Jenis Efektif & 2,582 & 2,521 & 2,771 & 2,292 & - & - \\
\hline Penyerapan & 2,754 & 2,585 & 2,564 & 1,897 & $\%$ & Maks 3\% \\
\hline Kadar Air & 0,145 & 2,174 & 3,156 & 0,489 & $\%$ & - \\
\hline Kadar Lumpur & 2,680 & 0,995 & 0,813 & 0,520 & $\%$ & $\begin{array}{l}\mathrm{AK}<1 \% \\
\mathrm{AH}<5 \%\end{array}$ \\
\hline Bobot Isi Gembur & 1,192 & 1,012 & 1,291 & 1,247 & $\mathrm{gr} / \mathrm{cm}^{3}$ & Min $1 \mathrm{gr} / \mathrm{cm}^{3}$ \\
\hline Bobot Isi Padat & 1,560 & 1,257 & 1,400 & 1,403 & $\mathrm{gr} / \mathrm{cm}^{3}$ & Min $1 \mathrm{gr} / \mathrm{cm}^{3}$ \\
\hline $\begin{array}{l}\text { Kekerasan } \\
\text { Agregat }\end{array}$ & - & - & 15,947 & 12,940 & $\%$ & Maks 30\% \\
\hline Keausan Agregat & - & - & 29,764 & 20,368 & $\%$ & Maks 40\% \\
\hline
\end{tabular}

Tabel 2. Hasil Pengujian Aspal

\begin{tabular}{|c|c|c|c|c|}
\hline Pengujian & Hasil & Spesifikasi & SNI & Keterangan \\
\hline Berat Jenis & $1,036 \mathrm{gr}$ & Min. 1 & $06-2441-1991$ & Memenuhi \\
\hline Penetrasi $\left(25^{\circ} \mathrm{C}, 5\right.$ detik) & $81,13 \mathrm{~mm}$ & $80-150$ & $06-2456-1991$ & Memenuhi \\
\hline Titik Lembek & $46,5^{\circ} \mathrm{C}$ & $46-150$ & $06-2434-1991$ & Memenuhi \\
\hline Titik Nyala & $285^{\circ} \mathrm{C}$ & $218-288$ & $06-2433-1991$ & Memenuhi \\
\hline Titik Bakar & $340^{\circ} \mathrm{C}$ & $>288$ & $06-2433-1991$ & Memenuhi \\
\hline
\end{tabular}

Berdasarkan hasil pengujian terhadap aspal yang digunakan diketahui bahwa aspal memenuhi standart spesifikasi yang ditentukan. Pengujian Marshall terhadap benda uji standar dilakukan untuk mengetahui nilai stabilitas, kelelehan (flow), dan karateristik campuran lainnya sehingga mendapatkan nilai Kadar Aspal Optimum (KAO) untuk pembuatan benda uji. Pada pengujian ini jumlah benda uji yang digunakan sebanyak 60 buah dengan masing - masing variasi kadar aspal sebanyak 3 buah dan berat masing - masing benda uji tersebut \pm 1200 gram dengan komposisi agregat seperti Gambar 1 berikut.

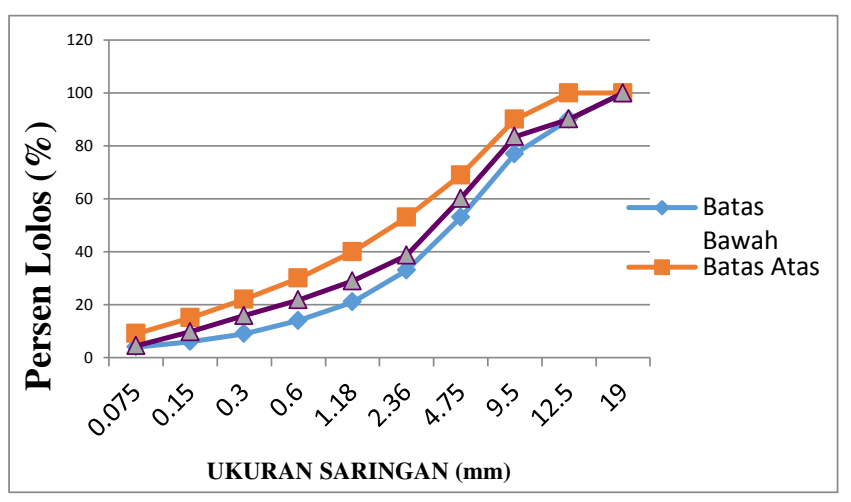

Gambar 1. Hasil Penggabungan Analisa Saringan Agregat 
Dari hasil analisa saringan terhadap campuran agregat diketahui bahwa agregat untuk gradasi rencana memenuhi spesifikasi berdasarkan standart Bina Marga Divisi 6 tahun 2010. Hasil rancangan agregat untuk pembuatan benda uji disajikan dalam Tabel 3 berikut :

Tabel 3. Komposisi Campuran Sebuah Benda Uji

\begin{tabular}{|c|c|c|c|c|c|c|c|}
\hline No & \multicolumn{2}{|c|}{ Material } & Normal & $\mathbf{1 5 \%}$ & $\mathbf{3 0} \%$ & $\mathbf{4 5} \%$ & $\mathbf{6 0} \%$ \\
\hline 1 & \multirow{2}{*}{$\begin{array}{c}\text { Agregat } \\
\text { Kasar }\end{array}$} & Agregat $1 / 2$ & $10 \%$ & $13,75 \%$ & $17,5 \%$ & $21,25 \%$ & $25 \%$ \\
\cline { 3 - 8 } & & Agregat $1 / 1$ & $30 \%$ & $41,25 \%$ & $52,5 \%$ & $63,75 \%$ & $75 \%$ \\
\hline 3 & \multirow{2}{*}{$\begin{array}{c}\text { Agregat } \\
\text { Halus }\end{array}$} & Abu Batu & $53 \%$ & $39,75 \%$ & $26,5 \%$ & $13,25 \%$ & $0 \%$ \\
\cline { 3 - 8 } & & Pasir & $7 \%$ & $5,25 \%$ & $3,5 \%$ & $1,75 \%$ & $0 \%$ \\
\hline
\end{tabular}

Dari hasil perhitungan Job Mix Formula didapat komposisi agregat untuk satu benda uji standar yaitu komposisi normal yang kemudian divariasikan dengan mengurangi jumlah persentase agregat halus sebanyak 15\%, 30\%, 45\% dan 60\%. Hasil pengujian Marshall benda uji standar untuk Kadar Aspal Optimum (KAO) dirangkum dalam Gambar 2. Dari hasil pembacaan pengujian Marshall benda uji yang tersaji pada Gambar 2 diperoleh kesimpulan bahwa Kadar Aspal Optimum (KAO) adalah sebesar $6,1 \%$.

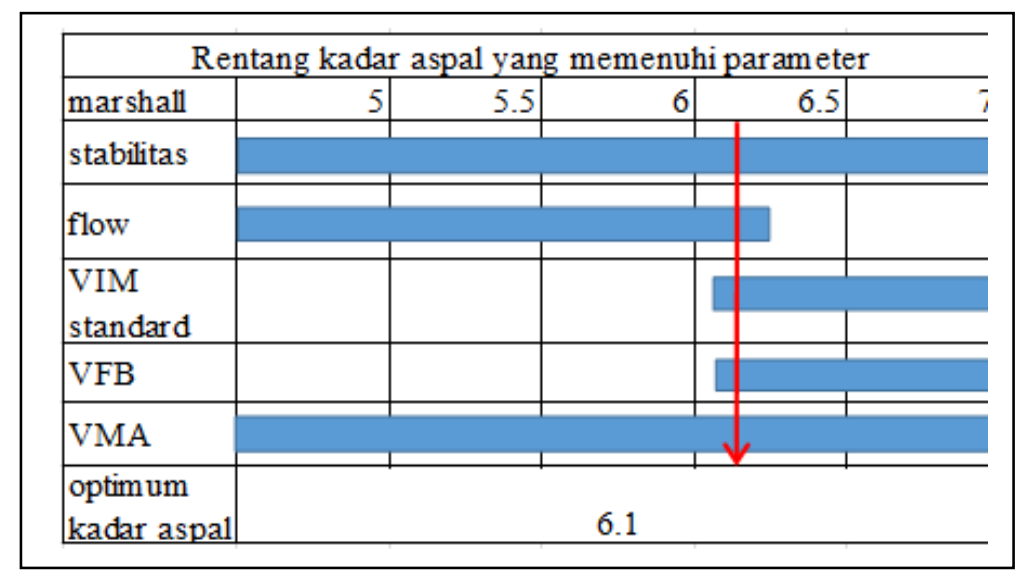

Gambar 2. Penentuan Kadar Aspal Optimum

\section{Analisis Campuran Aspal Porous}

Analisa campuran dengan gradasi agregat yang berbeda yaitu dengan melakukan pengurangan persentase agregat halus sebanyak 15\%, 30\%, 45\%, dan 60\% yang kemudian akan didistribusikan ke jumlah persentase agregat kasar terhadap berat total campuran untuk mendapatkan aspal porous dengan penggunaan kadar aspal optimum (KAO) sebesar 6,1\%.

Voids Filled by Asphalt (VFA) adalah rongga yang terisi oleh aspal yang terdapat dalam campuran beraspal. Hasil perhitungan VFA tersaji dalam Gambar 3. Dari hasil pengujian, nilai rongga terisi aspal atau VFA sesuai jumlah tumbukan yaitu 75, 50, dan 35 kali secara berurutan dengan variasi $15 \%$ memiliki nilai VFA sebesar $63,19 \%$; 51,50\%; 51,44\%. Pada variasi $30 \%$ memiliki nilai VFA sebesar 55,08\%; 46,81\%; 48,90\%. Pada variasi $45 \%$ memiliki nilai VFA sebesar 54,81\%; $49,87 \% ; 44,88 \%$. 


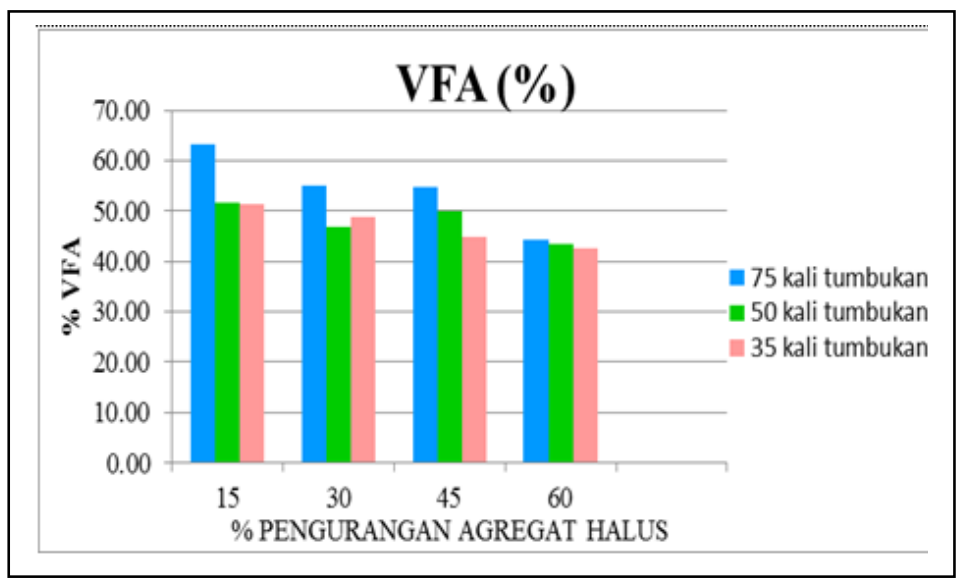

Gambar 3. Histogram VFA Campuran Dengan Modifikasi Pengurangan Persentase Agregat Halus

Pada variasi $60 \%$ memiliki nilai sebesar 44,16\%; 43,56\%; 42,62\%. Dari data tersebut diketahui bahwa semakin banyak pengurangan persentase agregat halus menyebabkan nilai persentase VFA menurun. Terlihat juga bahwa nilai VFA pada masing - masing tumbukan berbeda dengan persentase agregat yang sama dimana banyak jumlah tumbukan berbanding lurus dengan nilai VFA pada campuran. Pengaruh nilai VFA ini adalah terhadap kekuatan ikatan material agregat pada campuran adalah apabila semakin kecil maka perkerasan akan mengalami masalah durabilitas namun jika terlalu besar maka menjadi tidak ekonomis dan nilai stabilitas akan menurun. Namun, pada penggunaan perkerasan aspal poros semakin kecil nilai VFA maka akan mempercepat aliran air dari permukaan jalan secara vertical yang kemudian dialirkan menuju saluran samping.

Voids in Mixture (VIM) adalah rongga yang terdapat pada campuran beraspal. VIM dipengaruhi oleh kadar aspal, semakin meningkat kadar aspal maka rongga terisi aspal akan bertambah sehingga volume rongga yang terjadi akan berkurang. Hasil perhitungan nilai VIM tersaji dalam Gambar 4 berikut.

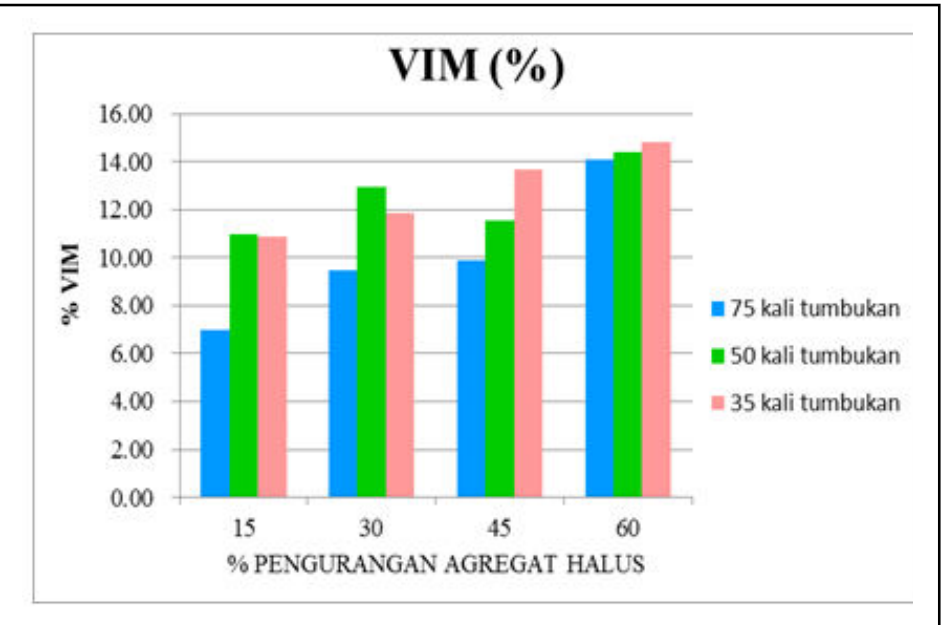

Gambar 4. Histogram VIM Campuran Dengan Modifikasi Pengurangan Persentase Agregat Halus 
Dari Gambar 4 didapat hasil rongga dalam campuran sesuai jumlah tumbukan yaitu 75, 50, dan 35 kali secara beurutan pada variasi $15 \%$ adalah sebesar $7 \% ; 10,95 \% ; 10,86 \%$. Pada variasi $30 \%$ adalah sebesar $9,49 \% ; 12,92 \% ; 11,86 \%$. Pada variasi $45 \%$ adalah sebesar 9,90\%; 11,57\%; 13,68\%. Pada variasi $60 \%$ adalah sebesar $14,09 \% ; 14,42 \% \%, 14.80 \%$. Dari data tersebut diketahui bahwa semakin banyak pengurangan persentase agregat halus dan penurunan jumlah tumbukan menyebabkan nilai persentase VIM semakin besar. Dalam aspal poros nilai VIM yang meningkat akan semakin cepat menyerap air dari permukaan jalan dan mengalirkannya ke saluran yang ada di samping jalan. Jika nilai VIM dalam campuran terlalu kecil maka air yang mengalir kedalam campuran aspal semakin lambat.

Voids in Mineral Aggregates (VMA) adalah rongga udara yang terdapat diantara mineral agregat dalam campuran beraspal, rongga tersebut termasuk rongga pada mineral yang terisi aspal. VMA dipengaruhi kadar aspal, gradasi bahan susun, jumlah tumbukan, dan pemadatan. Hasil perhitungan VMA tersaji dalam grafik histogram Gambar 5. Hasil tersebut menunjukkan bahwa nilai VMA pada campuran berdasarkan jumlah tumbukan 75, 50, dan 35 secara berurutan dengan variasi 15\% diperoleh kandungan rongga antara mineral agregat yaitu sebesar 19,22\%; 22,53\%; 22,58\%. Pada variasi $30 \%$ kandungan rongga antara mineral agregat sebesar 21,39\%; 24,25\%; 23,45\%. Pada variasi $45 \%$ kandungan rongga antara mineral agregat sebesar $21,74 \% ; 23,07 \% ; 25,02 \%$. Pada variasi $60 \%$ kandungan rongga antara mineral agregat sebesar 25,38\%; 25,55\%; 26,00. Dari data tersebut diketahui bahwa semakin besar pengurangan persentase jumlah agregat halus dan semakin sedikit jumlah tumbukan pada campuran menyebabkan nilai kandungan rongga antar butir agregat meningkat. Jika nilai VMA dalam campuran terlalu kecil maka campuran akan mengalami masalah durabilitas dan jika nilai VMA semakin besar maka campuran dapat menurunkan stabilitas dan tidak ekonomis diproduksi karena nilai penyerapan material terhadap aspal sangatlah tinggi.

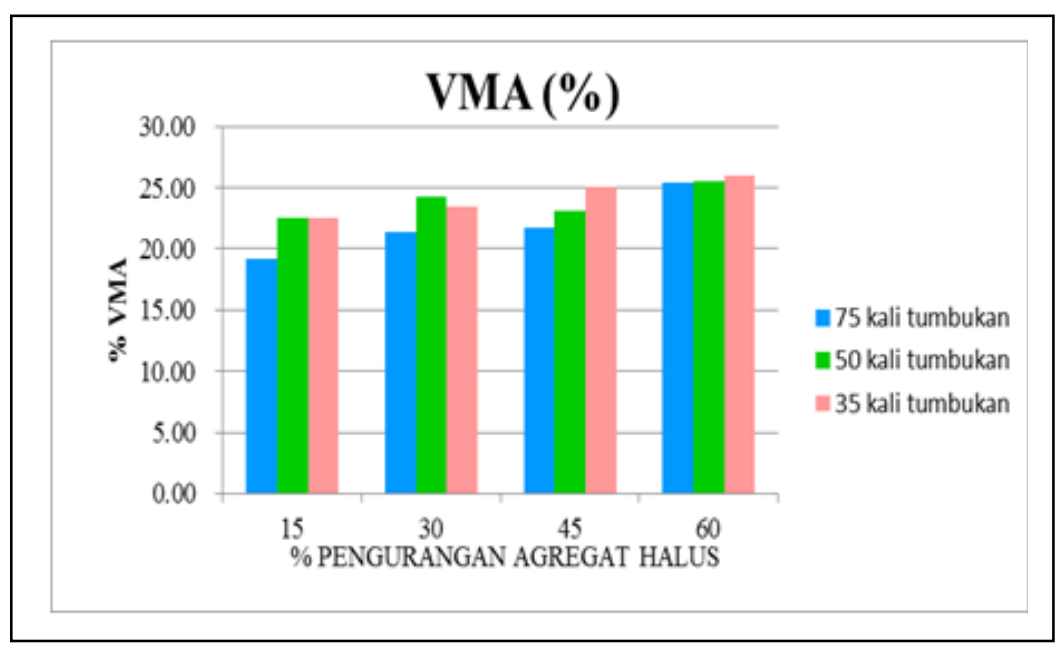

Gambar 5. Histogram VMA Campuran Dengan Modifikasi Pengurangan Persentase Agregat Halus

Stabilitas adalah besarnya beban maksimum yang dapat ditumpu oleh campuran beraspal yang dinyatakan dalam satuan beban. Stabilitas merupakan indikator kekuatan sebuah lapisan perkerasan. Nilai stabilitas pada campuran dipengaruhi oleh kekuatan agregat untuk menerima beban serta gradasi susunan campuran aspal. Syarat minimum stabilitas menurut Spesifikasi Umum Divisi VI, Bina Marga, 2010 untuk AC-WC adalah > $800 \mathrm{~kg}$. Hasil perhitungan nilai stabilitas campuran dengan modifikasi pengurangan jumlah agregat halus sebanyak 15\%, 30\%, 45\%, dan 60\% keseluruhan persentase total agregat halus terhadap total berat agregat campuran dengan kadar aspal optimum 
(KAO) yaitu 6,1\% dapat dilihat pada gambar 6. Berdasarkan hasil grafik diatas, diperoleh pada variasi pengurangan persentase agregat halus sebesar $15 \%$ dengan jumlah tumbukan masing - masing 75, 50, dan 35 kali secara berurutan yaitu $1419 \mathrm{~kg} ; 878 \mathrm{~kg} ; 842 \mathrm{~kg}$.

Pada variasi pengurangan persentase agregat halus sebesar 30\% yang didistribusikan ke jumlah persentase agregat kasar nilai stabilitas yaitu $1277 \mathrm{~kg} ; 638 \mathrm{~kg} ; 831 \mathrm{~kg}$. Pada variasi pengurangan persentase agregat halus sebesar $45 \%$ yang didistribusikan ke jumlah persentase agregat kasar nilai stabilitas yaitu $1205 \mathrm{~kg} ; 873 \mathrm{~kg} ; 658 \mathrm{~kg}$. Pada variasi pengurangan persentase agregat halus sebesar $60 \%$ yang didistribusikan ke jumlah persentase agregat kasar nilai stabilitas yaitu $714 \mathrm{~kg} ; 549 \mathrm{~kg} ; 517$ kg. Dari hasil ini diketahui bahwa pengurangan jumlah persentase agregat halus dan penambahan pada persentase agregat kasar membuat campuran mengalami penurunan nilai stabilitas. Jumlah tumbukan yang sedikit juga menyebabkan turunnya nilai stabilitas di masing - masing variasi. dari hasil ini diketahui bahwa nilai stabilitas semakin menurun apabila aspal semakin bersifat porous.

Langkah selanjutnya, model untuk aplikasi di lapangan dibuat dalam skala kecil berukuran $3 \mathrm{mx} 1 \mathrm{~m}$ tebal $5 \mathrm{~cm}$ menggunakan material yang sama dengan benda uji di laboratorium. Model dibuat dengan cara menghamparkan campuran aspal secara manual, baik pemanasan maupun pengadukan. Pemadatan dilakukan dengan hand compactor sebanyak 8 lintasan. Gambar 6 menunjukkan model aplikasi yang dibuat.

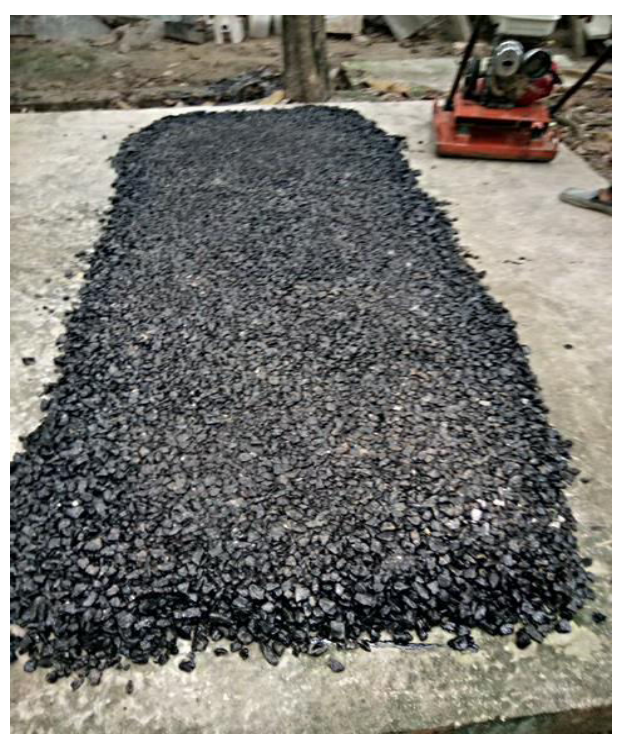

Gambar 6. Benda uji untuk aplikasi lapangan

Setelah benda uji selesai, dilakukan pengamatan porositas perkerasan. Air sebanyak 5 liter disiramkan pada area perkerasan seluas $3 \mathrm{~m}^{2}$ dimana hasilnya adalah seluruh air terserap dalam waktu 10 detik. Sehingga dapat ditaksir bahwa penyerapan air oleh perkerasan adalah $0,1667 \mathrm{liter} / \mathrm{m}^{2} /$ detik.

\section{KESIMPULAN DAN SARAN}

Penelitian ini telah menyelesaikan pengujian material, pembuatan rancangan campuran dan pengujian pada skala laboratorium, yang dilanjutkan dengan pembuatan model aplikasi lapangan skala kecil. Material yang telah di uji memenuhi sandar yang di syaratkan dan didapatkan kadar aspal optimum untuk campuran sebesar 6,1\% dari total berat campuran. Maksimum porositas yang didapat 
sebesar 14\%, hal ini terjadi pada uji tumbukan sebanyak 75 kali. Nilai stabilitas yang didapatkan untuk setiap pengurangan prosentase pasir menunjukkan penurunan nilai stabilitas berikut juga dengan perlakuan jumlah tumbukan semakin banyak jumalah tumbukan maka semakin tinggi nilai stabilitas. Berdasarkan visualisasi terhadap model lapangan, dapat dilihat bahwa dengan porositas yang dimiliki, campuran aspal yang dibuat mampu mengalirkan air cukup cepat.

Pada hasil yang didapatkan penurunan stabilitas seiring dengan bertambahnya porositas atau void maka perlu dilakukan penelitian lebih lanjut untuk komposisi tertentu agar didapat stabilitas yang stabil dan porositas yang cukup. Lapisan aspal poros ini harus diletakan diatas lapisan yang dibawahnya terjamin benar benar kedap air agar air tidak masuk kelapis pondasi jalan.

\section{DAFTAR PUSTAKA}

[1] Andiyanto. C. (2010). Pemilihan Teknik Perbaikan Perkerasan Jalan dan Biaya Penanganannya. Undergraduate thesis. Universitas Sebelas Maret. Malang

[2] Departemen Pekerjaan Umum Revisi 3 Divisi VI. (2010). Spesifikasi Pengujian Aspal. Yayasan Penerbit Pekerjaan Umum.

[3] Hardiyatmo H.C. (2009). Pemeliharaan Jalan Raya. Gadjah Mada University Press. Yogyakarta.

[4] Katsuji Nishijima, Shiego Higashi and Masaki Ikeuchi. (2009). Development of re-paved porous asphalt pavement method for reconstructing existing dense graded asphalt pavement into porous asphalt pavement using the in-place surface recycling method, Proceeding of 13th Conference of the Road Engineering Associationof Asia and Autralasia (REAAA), 9-15.

[5] M. Miradi, A.A.A. Moleenar, M.F.C van de Ven. (2009). Performance modeling of porous asphalt concrete using artificial intelligence, Road Materials and Pavement Design. ICAM 2009, pp.263-280.

[6] SNI 06-2432-1991, Metoda Pengujian Daktilitas Bahan-Bahan Aspal. Pusat Litbang Jalan Dan Jembatan. Bandung.

[7] SNI 06-2433-1991, Metoda Pengujian Titik Nyala Dan Titik Bakar Dengan Alat Cleveland Open Cup. Pusat Litbang Jalan Dan Jembatan. Bandung.

[8] SNI 06-2434-1991, Metoda Pengujian Titik Lembek Aspal Dan Ter. Pusat Litbang Jalan Dan Jembatan. Bandung

[9] SNI 06-2441-1991, Metoda Pengujian Berat Jenis Aspal Padat. Pusat Litbang Jalan Dan Jembatan. Bandung.

[10] SNI 06-2456-1991, Metoda Pengujian Penetrasi Bahan-bahan Bitumen. Pusat Litbang Jalan Dan Jembatan. Bandung.

[11] Sukirman S. (2010). Perencanaan Tebal Struktur Perkerasan Lentur. Nova. Bandung.

[12] Sukirman S. (2003). Beton Aspal Campuran Panas. Penerbit Granit. Jakarta

[13] Sukirman S. (2010). Perencanaan Tebal Struktur Perkerasan Lentur. Nova. Bandung. 